interact personally with a Teaching Assistant. The graph shows that funding for TA positions is the only factor that has tried to keep pace with the growing enrollments. We generally employ about 20 TA's per semester, at 20 hours per week (half-time), which still only results in about 1.5 TA's for each class of 230 students.

A considerable problem for the teaching program is that the research programs at Texas will often hire most of the astronomy graduate students as Research Assistants. Thus, we must hire some of our TA's from other departments (physics, engineering), and to try to train them for the job. Clearly, such TA's will be much more limited in the duties they can carry out. Also, many of the astronomy TA's today are foreign students who often have such a poor command of the English language that they are quite restricted in their usefulness.

\title{
Summary
}

Whether or not you feel that the Texas experience is directly or only partially applicable to your institution, it does indicate the ultimate potential of an undergraduate program. If all U.S. colleges would develop programs comparable to ours, the job market for astronomy teachers would increase by at least a factor of 10 ! Imagine the effect of that on astronomy as a career.

In researching this paper, I personally was surprised by the importance of intangible factors, and most particularly, the importance of the belief that undergraduate education is important and worthy of effort. This factor explains why growth was allowed to continue, even when the tangible rewards from it were not always evident.

\section{WORKSHOP FOR TEACHERS OF INTRODUCTORY ASTRONOMY}

\author{
George S. Mumford \\ Department of Physics and Astronomy, Robinson Hall, Tufts University, Medford, \\ Massachusetts 02155 U.S.A.
}

As interest in astronomy develops through missions to Mars, SETI, and heavenonly-knows-what earth-shaking new discoveries in the future, demand for astronomy courses at all levels will increase. Without adequate numbers of professional astronomers to teach them, persons from other fields will be thrown into the breech. Already a significant number of college students in the United States are receiving instruction from persons not trained in astronomy. I suspect that this is currently true world-wide, especially as physicists who adopt our field for their research on neutrinos or cosmic strings are assigned or volunteer to teach elementary courses. 
Comprehensive universities in the United States, some private (such as Harvard or Princeton) and others public (such as the University of California system or the University of Michigan) generally have several astronomers on their faculties who provide an extended program of courses. At another level are the four-year colleges. Some, such as our host for this colloquium, Williams College, have well-established astronomy programs; however, many others do not. Finally, in the American scheme of higher education, there are the junior or community colleges - two year institutions offering programs to a mixed clientele ranging from eighteen-year-olds to senior citizens. Seldom does one find an astronomer here. But, astronomy courses are popular and in demand and many of these institutions offer them at the introductory level. Since there are few astronomers associated with these places, often a volunteer versed in another discipline assumes the teaching function.

With funding from the National Science Foundation's program for the Enhancement of Undergraduate Faculty, a two-week workshop was run this past June at Tufts University for persons with a minimum of three years of college-teaching experience who had not had graduate training in astronomy but found themselves teaching introductory courses. Of particular concern were persons from institutions that likely did not have access to modern observational facilities to train students. Despite the fact that announcements of the program did not go out until early April 1988 , by mid-May there were 25 completed applications for 20 slots, plus inquiries from another dozen persons. The program was repeated in 1989.

Eleven of the applicants were from community colleges; five from public fouryear colleges; and the rest from private four-year colleges. Thirteen of the applicants held Ph.D.'s: eight in physics; two in physical chemistry; and one each in chemistry, education, and science education. These degrees were from universities that are recognized sources of research-oriented doctorates. Three additional doctorates, not Ph.D.'s, were in education, while the remainder of the applicants held masters' degrees, including five in education or teaching. All degrees had been earned rather uniformly throughout the period 1960 to 1982 . There was a comparable even distribution in the ages of the applicants.

In general, members of the group were conversant with modern textbooks, used many laboratory exercises, and had access to portable telescopes. Most, however, needed instruction in how to set up, orient, and use such an instrument; many were unaware of resources for slides, computer software and other materials. At a more mundane level, several consistently inverted the magnitude scale, leading to some peculiar looking color-luminosity diagrams; most had, at best, only a cursory knowledge of various astronomical coordinate systems.

Our intent in the workshop was to minimize lecturing and maximize hands-on activities that simulate some of the steps an astronomer makes in reducing data and obtaining a result. To accomplish this, a variety of projects were used including many of the Laboratory Exercises in Astronomy from Sky Publishing Corporation. Further, beyond having participants work their way through the various exercises, we hoped to get them to think critically about what they were doing. While some exercises are quite complete, many can be improved. Not only are data frequently 
out of date, but also accidental and systematic errors in the measurements are sometimes ignored. Participants were asked to think about such matters. For each of the activities he or she completed a brief questionnaire evaluating the materials used and suggesting improvements.

We are teaching young astronomers; we are teaching teachers; but this group has apparently escaped the net. How many does it contain? It's difficult to say until someone makes a comprehensive survey, but my guess is several hundred in the United States alone.

It seems to me that there are two rather different ways to approach the problem of having elementary astronomy courses taught by nonastronomers. On the one hand, a statement from the profession urging the employment of only those with graduate training in the field to teach in these programs would increase employment opportunities in academia for many graduates who cannot otherwise find jobs related to their discipline. But, while this might be possible in the long run, because of the economics of the situation an alternative solution is required. Simply stated, this alternative is to identify, instruct, and support those persons who are obviously interested in learning about their adopted field. The structures and mechanisms to accomplish this exist, and we should use them.

\section{Discussion}

R.R. Robbins: In the mid-1970's, I presented NSF-Chautauqua workshops on the teaching of astronomy to just the type of participants you had, and the problems were the same. But I gave these to hundreds of teachers at 12 to 15 education centers across the country, and the demand was so great I could have done it over and over again at every location. Fifteen years later the problem has not changed at all! We must find some organized mechanism to update our teachers, or we will be meeting again around the year 2000 and noting that the problem is still with us.

G.S. Mumford: This is the very reason why $I$ presented this talk.

R.J. Dukes, Jr.: I teach in a physics department of 3 astronomers and 4 physicists. All of the physicists have taught the introductory astronomy course. After 10 years of subtle observation, I have found that the physicists generally do as good a job on this course as the astronomers!

J.C. LoPresto: Many Planetarium directors have little or no background in astronomy. 